a given measure of distilled water, the volume of distilled water equal to the bulk of the body, the weight of the body when immersed in distilled water, allowance being made for the difference between the weight of the counterpoise in vacuo and in air.

The chief difficulty is to procure a body of sufficient size not too heavy for a delicate balance. It seems not improbable that a material may be found which, when formed into a globe or a drum, and filled with air merely for the sake of lightness, shall not exceed a pound in weight, and yet may be of such a size as, with a balance turning with the tenth of a grain, may, under the occasional correction of exact methods, enable those who engage in meteorology merely for the sake of occupation, to add to their register a near approximation to the daily density of air. If such a body, equal to or exceeding a cubic foot in volume, cannot be provided with the requisite qualities, namely, lightness, permanence in figure, impermeability to air and moisture, and the being susceptible of having its expansions and contractions, under changes of temperature, reduced to rule, a glass globe capable of displacing 600 cubic inches of air, with a little more pains and attention, can be made to serve the purpose recommended in this communication.

\title{
2. Researches on Chinoline and its Homologues. By C.
} Greville Williams. Communicated by $\mathrm{Dr}$ T. Anderson.

In this inquiry, which is an extension of an investigation published in the Transactions for last year, the author examines the connection which has been said to exist between chinoline and quinine, and shows that they bear no simple relation to each other. $\mathrm{He}$ states, also, that the supposed analogy between the action of heat on quinine and the hydrated oxide of tetramethyl-ammonium does not exist, and that the assertions which have been made regarding the possibility of the formation of quinine from the leukol of coal-tar are founded on error. He then, after showing that chinoline from cinchonine had not previously been obtained in a state of purity, gives the history and composition of the platinum, gold, and palladium salts; also the nitrate, bichromate, and binoxalate.

He describes two new classes of salts formed by the chlorides of cadmium and uranyl with organic bases, and gives the analysis of 
their compounds with chinoline. Then follows a determination of the vapour density of chinoline, and an examination of the action of the iodides of the alcohol radicals on the base, and some of the products of the decomposition of the hydriodates of the ammonium bases so formed.

He also examines the chinoline series as it is obtained from coaltar, and proves the presence, in addition to chinoline, of lepidine, and a new base, "cryptidine."

In the course of the investigation, the following compounds were analysed :-

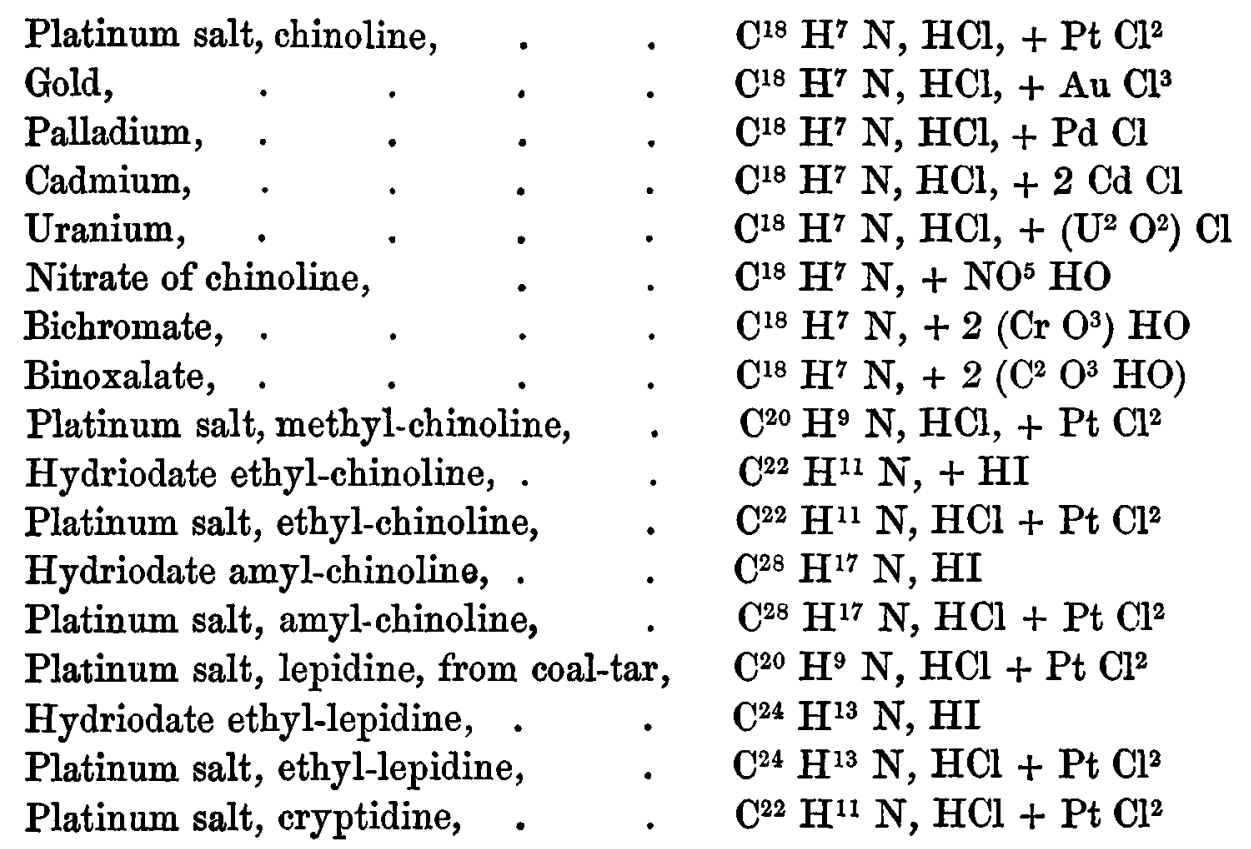

3. On Fermat's Theorem. By H. Fox Talbot, Esq., F.R.S.

The author gave a simple demonstration of the proposition, that $a^{n}=b^{n}+c^{n}$ is impossible, when $n>2$, and either of the numbers, $a, b, c$, a prime number.

4. On the Transmission of the Actinic Rays of Light through the Eye, and their relation to the Yellow Spot of the Retina. By George Wilson, M.D.

In 1849 the learned Swiss philosopher Wartmann stated, in his "Deuxième Mémoire sur le Daltonisme," p. 40, that " the eye 